\title{
QUANTITATIVE ANALYSIS OF TOTAL PHENOLICS, FLAVONOIDS AND ANTIOXIDANT ACTIVITY OF OLIVE FRUITS (OLEA FERRUGINEA) BASED ON GEOGRAPHICAL REGION AND HARVESTING TIME IN ZHOB DISTRICT, PAKISTAN
}

\author{
MASOOD, A. ${ }^{1}$ - MANZOOR, M. ${ }^{2}$ - ANJUM, S. ${ }^{1}$ - ACHAKZAI, A. K. K. ${ }^{1}-$ SHAH, S. H. ${ }^{3}-$ \\ RizWAN, S. ${ }^{4}$ - TAREen, R. B. ${ }^{1}$ - IsMaIl, T..$^{1,5^{*}}$ - PONYA, Zs. ${ }^{5}-$ MushtaQ, A. ${ }^{4}$-Ullah, A. ${ }^{6}$ \\ ${ }^{1}$ Department of Botany, University of Balochistan, Sariab Road, 87300 Quetta, Pakistan \\ ${ }^{2}$ Department of Botany, Sardar Bahadur Khan, Women's University, Brewery Road, Quetta, \\ Pakistan \\ ${ }^{3}$ Department of Statistics University of Balochistan, Sariab Road, 87300 Quetta, Pakistan \\ ${ }^{4}$ Department of Chemistry, Sardar Bahadur Khan, Women's University, Brewery Road, Quetta, \\ Pakistan \\ ${ }^{5}$ Department of Plant Protection and Production, Szent István University Kaposvár Campus, \\ Hungary \\ ${ }^{6}$ Centre of Advanced Studies in Vaccinology and Biotechnology (CASVAB), University of \\ Balochistan, Pakistan \\ ${ }^{*}$ Corresponding author \\ e-mail: tariq.ismail@ szie.hu \\ (Received $7^{\text {th }}$ Mar 2020; accepted $11^{\text {th }}$ Aug 2020)
}

\begin{abstract}
Present study aims to explore fluctuating levels of total phenolic content (TPC), total flavonoid content (TFC) and antioxidant activity (AA) in fruits of Olea ferruginea Royle with respect to changing altitude, slope direction and harvesting time in District Zhob, Pakistan. Sampling was performed from three altitudes with approximate difference of 183 meter (600 feet) between each point at north facing and south facing slopes. Fruits were collected from twenty trees around each point, thoroughly washed with running water, shade dried, grinded and extracted against four solvents i.e., water, acetone, $80 \%$ ethanol and $80 \%$ methanol. Extracts were further analyzed for TPC, TFC and AA (as DPPH radical scavenging activity). Solvent efficiency appears as acetone $>80 \%$ methanol $>80 \%$ ethanol $>$ water for maximum extraction of TPC, TFC and AA. Analysis of variance (ANOVA) and least significance difference (LSD) tests depicted that olives grown on south facing slopes have significantly higher TPC values as compared to north facing slopes whereas a reverse pattern was observed for TFC. Minimum TPC, TFC and AA was recorded in olives collected from middle altitude that increased with altitude. TPC, TFC and AA showed an increase when fruit fully matured while a drop was observed when green fruit turned purple.
\end{abstract}

Keywords: altitude, slope, ethanol, methanol, acetone

\section{Introduction}

Zhob district, Balochistan is well recognized for its naturally occurring population of wild olive trees. It is located in an agro-ecological zone and occupies 126,719 hectares of agricultural land. It is significant for agriculture and well known for its naturally occurring wild olive forest population. Olive and its various components are valued for their 
functional food components and bioactive nutrients that promote health (Ghanbari et al., 2012).

The fruits of Olea ferruginea are edible, pickled and utilized as appetizers, antidiabetics and has emmenagogue substances. Olives fruits oil is efficient in oleic acid, utilized for curing scabies, typhoid, eye burning, jaundice, biliousness, toothache and teeth caries (Zabihullah et al., 2006; Ahmad, 2007). Fresh fruit of Olea ferruginea Royle in summer season are collected, dried and recommended to diabetics in winter season for reducing blood glucose level in District Attok, Pakistan (Ahmad et al., 2009).

Fruit of Olea ferruginea is commercially overlooked and underutilized in Pakistan due to its smaller size apparently. Cultivated varieties of Olive hold important place commercially especially in pharmaceutical and food industry. Phytovhemical composition varies in accordance with light availability in slopes, and altitudes (Måren et al., 2015) and on ripening stages. The microclimate has strong relationships with the direction of slope of the area as it influences the topography and the amount of solar radiation received by a specific slope (Sariyildiz et al., 2005). North facing slopes receive minimum amount of radiation and are therefore cool, moist and subject to slow changes in seasonal and daily microclimate. South facing slopes, however, receive maximum solar radiation so they are typically hot and dry and subject to rapid changes in seasonal and diurnal microclimate. Studies have proven that at different stages of development of the plant, the quality and the quantity of total phenols change (Amiot et al., 1986).

Cultivated varieties of Olive hold important place commercially especially in pharmaceutical and food industry. Few studies are available on phenolic contents and antioxidant activities of fruit of Olea ferruginea and no work is conducted on fluctuation in phenolics and antioxidant activities of olive fruit with changing slopes, altitudes and ripening stages. Present study deals with these issues. It can contribute to the identification of the best harvesting time, elevation and slope direction that can help to avail maximum phytochemical ingredients of fruit. The main objective of this study is to unveil the influence of geographical positioning and maturation stage on the level of TPC, TFC and AA of Olea ferruginea fruit in an area with forest ecosystem and huge climatic and geological variations.

\section{Materials and methods}

Geographical representation of the area with the marked slopes and altitudes were taken. The area was first studied and discussed in the Department of Excellence in Mineralogy, University of Balochistan with the help of toposheets of district Zhob. Brunton ${ }^{\circledR}$ Compass and Global Positioning System (GPS) were used to select the sites for sample collection. The area map was prepared in Geological survey of Pakistan Quetta (Fig. 1). Olea ferruginea was identified with Flora of Pakistan (Grohmann, 1974) and was confirmed by Dr. Rasool Bakhsh Tareen (qualified plant Taxonomist, University of Balochistan Quetta).

On the basis of contrasting features of north facing and south facing slopes, these two type of slopes were chosen for sampling at different altitudes, at different growth stages of fruit.

The microclimate of area was evaluated with the help of monthly average data of rain fall, relative humidity and temperature for the year 2017 was obtained from Regional Metrological Centre, Pakistan Metrological Department. The $10^{\text {th }}$ January was the coldest day of the year with $-5^{\circ} \mathrm{C}$ while the $15^{\text {th }}$ June was the hottest day of the year with $41^{\circ} \mathrm{C}$. Maximum rainfall was observed on the $14^{\text {th }}$ November $(28 \mathrm{~mm})$ (Fig. 2). 


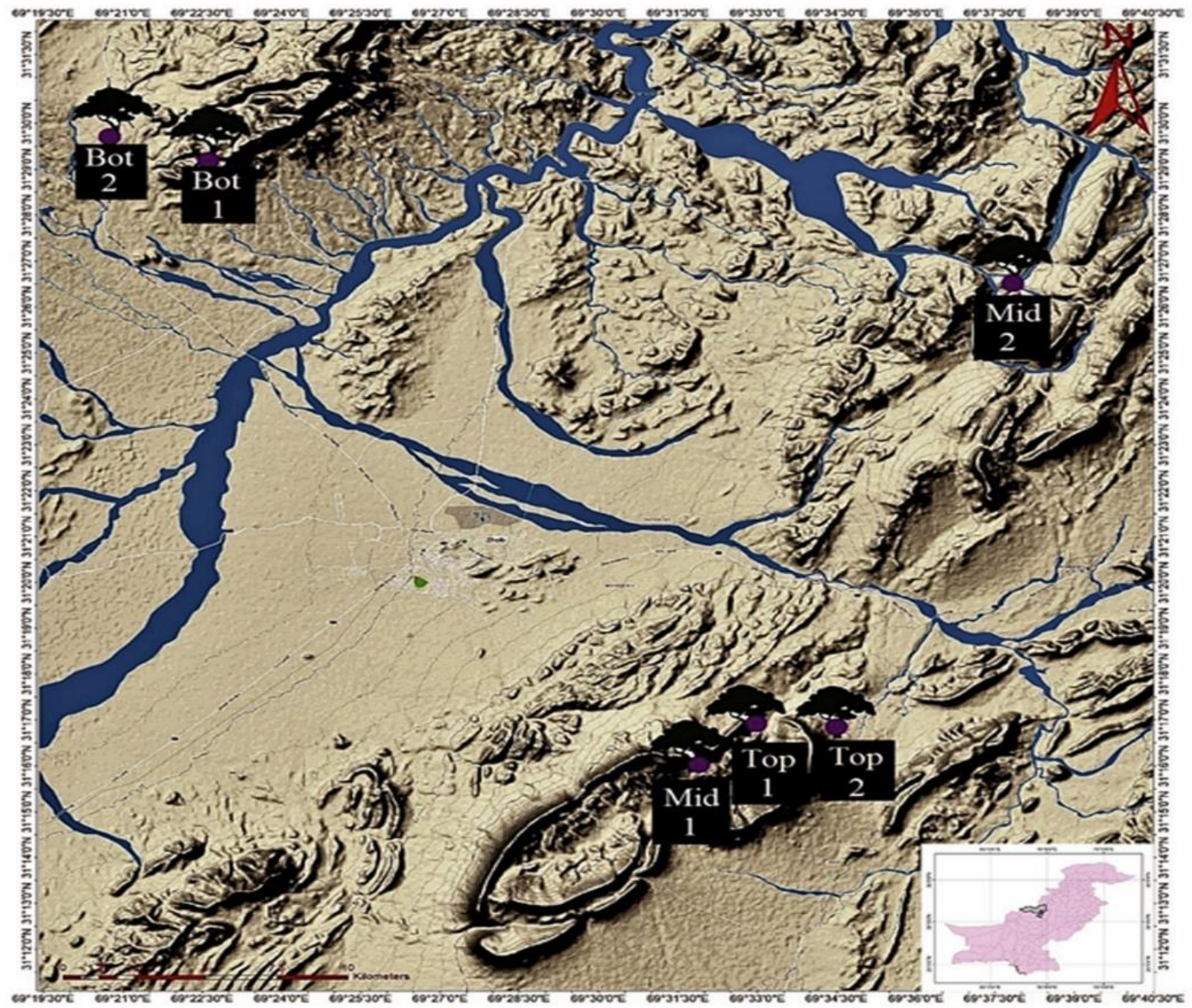

Figure 1. Sampling area map prepared on Terra incognita and Geographic Information System(GIS)
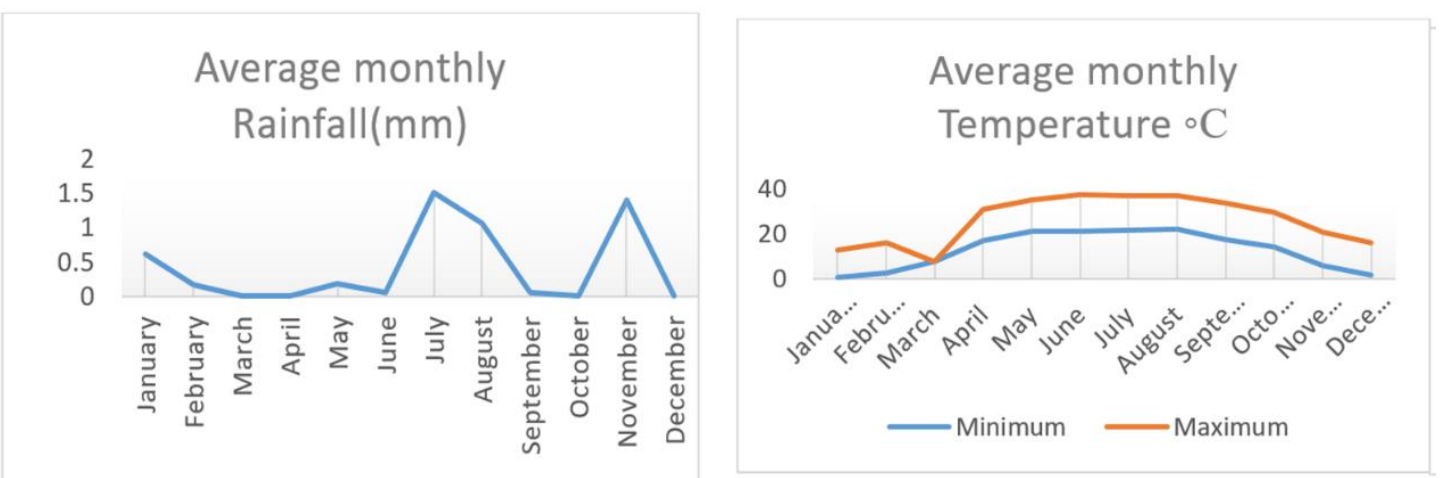

Figure 2. Metrological data of average monthly rainfall and average monthly temperature for the year 2017 obtained from Regional Metrological Centre, Metrological Department Pakistan

\section{Chemicals and reagents}

The following chemicals and reagents were used: Methanol (for HPLC $\geq 99.9 \%$ Sigma-Aldrich), Acetone (Sigma-Aldrich), Ethanol (Sigma-Aldrich), Distilled water, 
Folin-Ciocalteu's phenol reagent (purchased from $\mathrm{BDH}$ ), $\mathrm{Na}_{2} \mathrm{CO}_{3}, \mathrm{NaNO}_{2}, \mathrm{AlCl}_{3}$, $\mathrm{NaOH}$, Gallic acid, Catechin, diphenyl-picrylhydrazyl (DPPH), Butylated hydroxytoluene (BHT).

\section{Fruit sampling}

Local community call Zhob olives "Shnaney", while in urdu olives are known as Zaitoon. Stratified randomized sampling was conducted thrice in a year during crop year 2017-18. North facing and south facing slopes with dense population of test species were further divided in three strata based on elevation difference of approximately 600 feet in between each point. Around each point sampling was performed in a fashion to maintain height and slope direction with the help of Global Positioning System and Brunton compass (Table 1). First fruit sampling was conducted on $26^{\text {th }}$ June when green olives appeared on trees, second time purple, ripe olives were picked on $26^{\text {th }}$ August while last sampling was conducted on $26^{\text {th }}$ October when fruit color turned mature blackish purple. From each sampling site fruits were picked randomly from twenty trees and mixed in one zip lock bag to prepare a representative batch of specific site.

Table 1. Coordinates, elevation and slope direction of sampling sites recorded with Brunton ${ }^{\circledR}$ Compass and Global Positioning System (GPS)

\begin{tabular}{c|c|c|c|c|c|c}
\hline S.No. & $\begin{array}{c}\text { Sampling site } \\
\text { code }\end{array}$ & $\begin{array}{c}\text { Slope } \\
\text { direction }\end{array}$ & Dip & Latitudes & Longitudes & $\begin{array}{c}\text { Elevation } \\
\text { (Meters) }\end{array}$ \\
\hline 1 & TOP 1 & North facing & $45^{\circ} \mathrm{N}$ & $31^{\circ} 16.637 \mathrm{~N}$ & $069^{\circ} 32.033 \mathrm{E}$ & $1941 \mathrm{~m}$ \\
2 & MID 1 & North facing & $10^{\circ} \mathrm{N}$ & $31^{\circ} 2957.98 \mathrm{~N}$ & $069^{\circ} 2229.76 \mathrm{E}$ & $1758 \mathrm{~m}$ \\
3 & BOTTOM 1 & North facing & $65^{\circ} \mathrm{N}$ & $31^{\circ} 3022.15 \mathrm{~N}$ & $069^{\circ} 2058.66 \mathrm{E}$ & $1576 \mathrm{~m}$ \\
4 & TOP 2 & South facing & $20^{\circ} \mathrm{S}$ & $31^{\circ} 17.0690 \mathrm{~N}$ & $069^{\circ} 32.836 \mathrm{E}$ & $1944 \mathrm{~m}$ \\
5 & MID 2 & South facing & $25^{\circ} \mathrm{S}$ & $31^{\circ} 17.42 \mathrm{~N}$ & $069^{\circ} 3443.19 \mathrm{E}$ & $1758 \mathrm{~m}$ \\
6 & BOTTOM 2 & South facing & $15^{\circ} \mathrm{S}$ & $31^{\circ} 2705.49 \mathrm{~N}$ & $069^{\circ} 3548.88 \mathrm{E}$ & $1576 \mathrm{~m}$ \\
\hline
\end{tabular}

\section{Laboratory work}

\section{Processing}

After coming back from field, all fruits of one batch were washed thrice with running water and spread on clean white cloth sheet in a dark aerated room. Fruits were mixed daily and left like that for a month until hard dried fruits were obtained. Then dried fruits were grinded in an electrical grinder to obtain pasty powder.

\section{Extraction}

Powdered fruit was extracted in $80 \%$ methanol, $80 \%$ ethanol, acetone and water. Extraction was done as per method of Abideen et al. (2015). 50-gram plant material was mixed with $100 \mathrm{ml}$ of each solvent and the mixture was kept in a shaking water bath $(\mathrm{Memmert} \mathrm{GmbH})$ for 3 hours maintaining the temperature at $40^{\circ} \mathrm{C}$. After 3 hours the flasks were cooled to room temperature and then centrifuged at a speed of $4500 \mathrm{rpm}$ for 15 minutes. Then the supernatant was collected in caped glass tubes and kept at $4^{\circ} \mathrm{C}$ and was used for further analysis. 


\section{Quantitative determination of Polyphenols}

\section{Total Phenolic Content (TPC)}

The total phenolic content in fruit extracts were determined by applying some modifications to the procedure described by Folin and Denis (1912). Briefly, $0.5 \mathrm{ml}$ of extract was placed in a test tube, distilled water was added to make the final volume of $17 \mathrm{ml}$. To the solution, $1 \mathrm{ml}$ of Folin-Ciocalteu reagent was added and then after 8 minutes $2 \mathrm{ml}$ of $7 \%$ sodium carbonate solution was added. After 30 minutes of incubation in the dark, the absorbance was measured at $765 \mathrm{~nm}$ at Shimadzu UVVisible Spectrophotometer (UV 160). Gallic acid was used to prepare a set of standards to build a calibration curve. The total phenolic content was expressed as mg of gallic acid equivalent (GAE) per gram of dried fruit.

\section{Total Flavonoid Content (TFC)}

The total flavonoid content of fruit extracts was determined by making a few changes to the method described by Dewanto et al. (2002). Briefly, $1.0 \mathrm{ml}$ of fruit extract solution was placed in a volumetric flask, $5 \mathrm{ml}$ of distilled water was added to it and then $0.3 \mathrm{ml}$ of $5 \% \mathrm{NaNO}_{2}$ was poured into it. The solution was mixed and incubated for 5 minutes at room temperature. Afterwards, $0.6 \mathrm{ml}$ of $10 \% \mathrm{AlCl}_{3}$ was added and the second incubation was performed for 5 minutes at room temperature. Finally, $2 \mathrm{ml}$ of $1 \mathrm{M} \mathrm{NaOH}$ solution was added and then a volume of $10 \mathrm{ml}$ was achieved by adding distilled water. The absorbance was read at $510 \mathrm{~nm}$ using Shimadzu UV-Visible Spectrophotometer (UV 160). All the samples were analyzed in triplicate and the results were expressed as $\mathrm{mg} / \mathrm{g}$ of Catechin.

\section{Antioxidant activity assay}

The antioxidant activity of fruit extracts were measured by applying the diphenyl-picrylhydrazyl (DPPH) radical degradation method (Queiroz, 2009) with slight modifications. Briefly, $0.5 \mathrm{ml}$ of fruit extract was added in an equal volume of ethanolic solution of DPPH $(0.1 \mathrm{mM})$. The solution was mixed and incubated for 30 min in the dark at room temperature. All the samples were prepared and analyzed in triplicate and the absorbance was noted at $517 \mathrm{~nm}$ by means of a Shimadzu UV-Visible Spectrophotometer (UV 160). BHT (Butylated hydroxytoluene) was used as standard control. Inhibition of free radical by DPPH was calculated with Eq. 1 .

$$
\text { Antioxidant activity }(\%)=\frac{A_{\text {blank }}-A_{\text {sampl }}}{A_{\text {blank }}} \times 100
$$

where $A_{\text {blank }}$ is the absorbance of the control reaction mixture without the sample and $\mathrm{A}_{\text {sample }}$ is the absorbance of the sample under investigation.

\section{Statistical analysis}

All the results obtained from chemical analysis were processed on MINITAB software to obtain interaction plots that could reveal any relations between the parameters under consideration i.e., TPC, TFC and AA according to changing slopes, altitudes and plant development stages. STATISTIX software was used to perform analysis of variance (ANOVA) and Least Significance Difference (LSD): a statistically significant difference between groups was true if $p$-values were found less than 0.05 . 


$$
-18 \text { - }
$$

\section{Results and discussions}

The fruits of Olea ferruginea are edible, pickled and utilized as appetizers, antidiabetics, and an olive oil source efficient in oleic acid, utilized for curing scabies, typhoid, eye burning, jaundice, biliousness, toothache and teeth caries (Zabihullah et al., 2006; Ahmad, 2007). Fruit of Olea ferruginea is commercially overlooked and underutilized in Pakistan due to its smaller size apparently. Free radicals impair the proper functioning of the immune system leading to the various disease conditions. Flavonoids are naturally occurring phenolic compounds in plants which have antioxidant effect (Imaga et al., 2010).

\section{Slopes}

South facing slopes were found to make TPC of olive fruits higher when compared with phenolics of olives collected from north facing slopes (Fig. 3a,b,c). Results showed a reverse pattern in olives extracted in $80 \%$ Methanol (Fig. 3d). TFC of olive fruits also show the same pattern of fluctuation as seen in TPC except for slopes i.e., north facing slopes showed higher flavonoid content (Fig. 4a,c,d) whereas acetone extracts behaved oppositely (Fig. $4 b$ ).
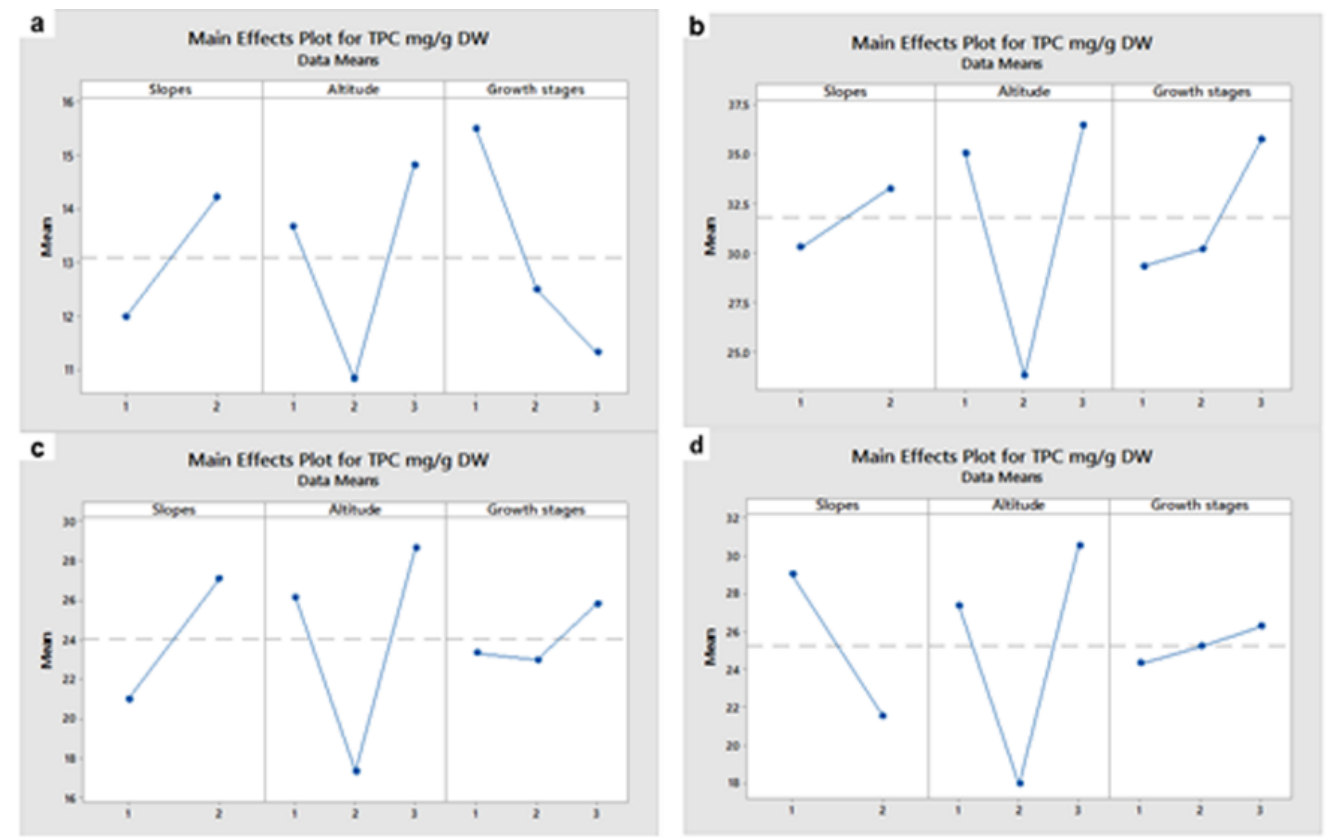

Figure 3. Main effect plot for total phenolic contents (TPC as $\mathrm{mg} / \mathrm{g}$ ) of Olea ferruginea Royle fruits with respect to slope, altitude, growth stages in four extraction solvents. Slopes: $1=$ North facing, 2= South facing; Altitude: $1=$ Top 2=Middle 3=Bottom; Growth stages: 1= Green fruits; $2=$ Purple ripened fruits; $3=$ Blackish mature fruits. Solvents: $a=$ water, $b=$ acetone, $c=80 \%$ ethanol, $d=80 \%$ methanol

\section{Altitude}

Generally, there is an overall decline in TPC, TFC and DPPH radical scavenging activity from the highest to middle altitude while a sudden boost was noted again in fruits collected from bottom of hills i.e., the lowest altitude. Pattern remained similar in all solvent extracts (Figs. 3,4,5). 

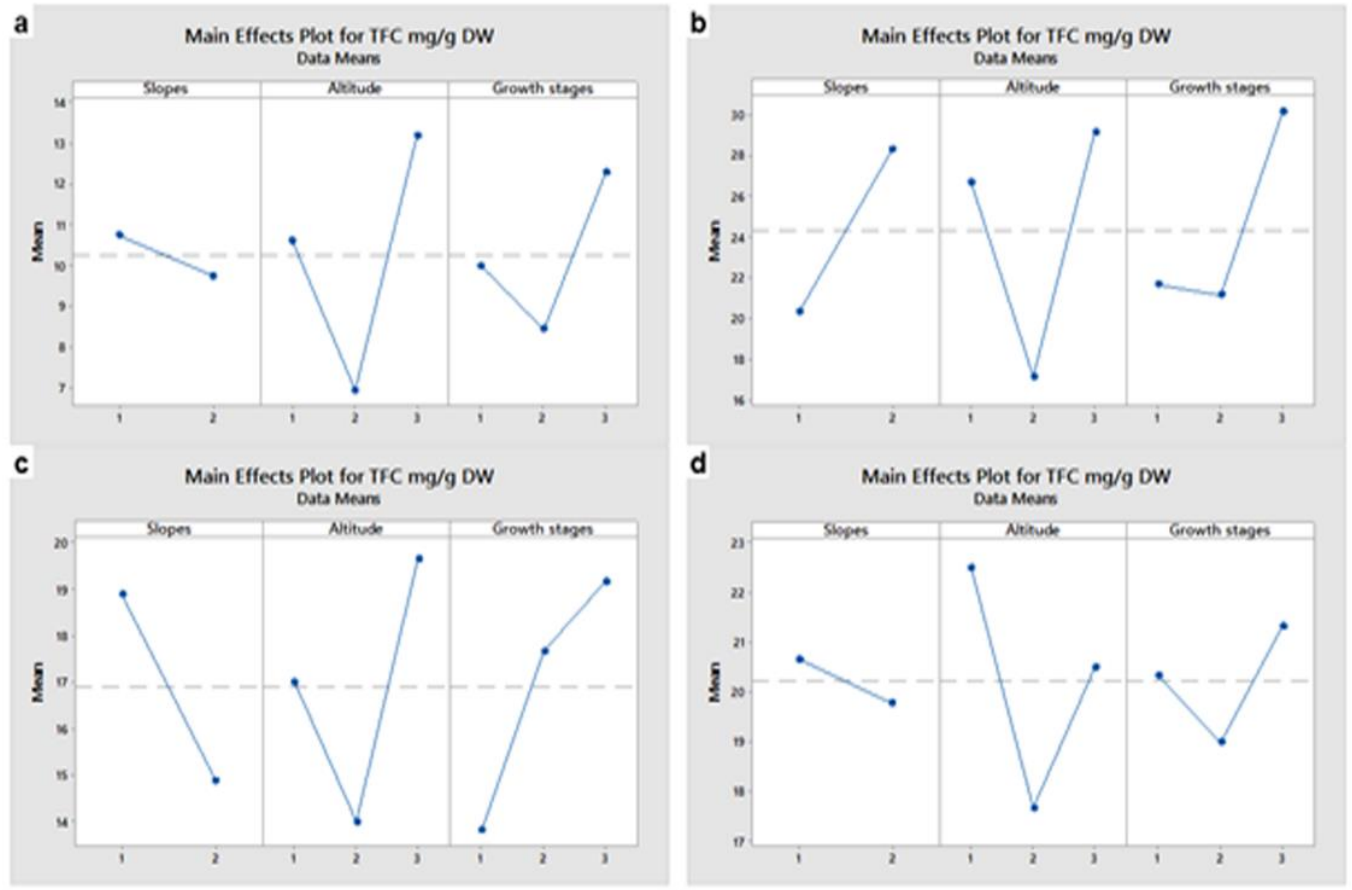

Figure 4. Main effect plot for total flavonoid contents (TFC as $\mathrm{mg} / \mathrm{g}$ ) of Olea ferruginea Royle fruits with respect to slope, altitude, growth stages in four extraction solvents. Slopes: $1=$ North facing, $2=$ South facing; Altitude: $1=$ Top 2=Middle 3=Bottom; Growth stages: $1=$ Green fruits; $2=$ Purple ripened fruits; $3=$ Blackish mature fruits. Solvents: $a=$ water, $b=$ acetone, $c=80 \%$ ethanol, $d=80 \%$ methanol
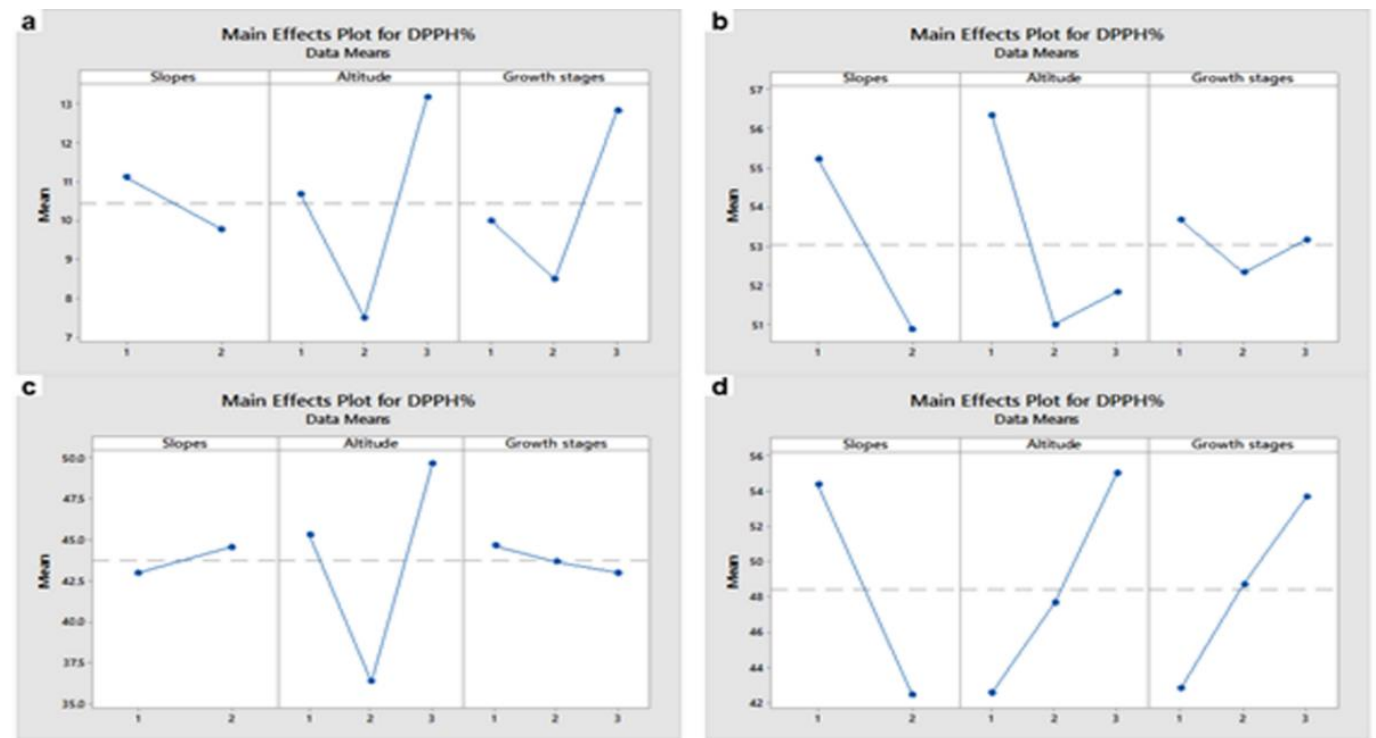

Figure 5. Main effect plot for Antioxidant activity (AA) as DPPH radical scavenging activity

(\%) of Olea ferruginea Royle fruits with respect to slope, altitude, growth stages in four extraction solvents. Slopes: $1=$ North facing, $2=$ South facing; Altitude: $1=$ Top $2=$ Middle $3=$ Bottom; Growth stages: $1=$ Green fruits; $2=$ Purple ripened fruits; $3=$ Blackish mature fruits. Solvents: $a=$ water, $b=$ acetone, $c=80 \%$ ethanol, $d=80 \%$ methanol 


\section{Growth stages}

Total phenolics of olive fruits increase with maturation and the highest levels were observed at the last maturation stage in the present study that supports the results of Bouaziz et al. (2004) in Olea europea. Present study is in agreement with Sharma et al. (2017) who concluded that ripened fruits of Olea ferruginea can serve as a good source of natural antioxidants. Peculiarly all phytochemical attributes evaluated (TPC, TFC and AA) in present study showed a steep drop at the second maturation stage of fruit while a maximum increase was observed in the last maturation stage when fruit turned blackish from purple (Figs. 3,4,5) except for TPC of olive fruits in aqueous extract, TFC and AA of $80 \%$ ethanol extracts of Olea ferruginea that came out differently (Figs. 3a, 4c, 5c).

Total phenolics increase with maturation and the highest levels were observed at the last maturatiom stage in Olea europea. A positive corelation between total phenolic content and antioxidant activity was also recorded. Antioxidant activity also increased with fruit maturation (Bouaziz et al., 2004).

\section{Extraction solvent}

In the recovery process, the extraction solvent plays a fundamental role. In most experiments, either ethanol or methanol was used to extract plant material (Poudyal et al., 2010; Ahmad-Qasem et al., 2013; Kamran, 2016). In food products, ethanol is the predominant solvent but $80 \%$ of methanol is known to be the most active solvent in olive leaf biphenols (Malik and Bradford, 2008). Boiling water has also been used for the extraction of biphenols in some of the studies (Pereira et al., 2007; Malik and Bradford, 2008). Most of the phenolic compounds are thought to be present chiefly in free form and can be easily extracted by alcoholic solvents (Hung and Duy, 2012).

Result of analysis performed to examine level of TPC, TFC and AA of Olea ferruginea fruits showed significant differences when the fruit was harvested at different ripening stages and from two slopes and three altitudes (Table 2).

Table 2. LSD test of TPC, TFC and AA at different slopes, altitudes, growth stages in Olea ferruginea fruits extracted in four different solvents

\begin{tabular}{|c|c|c|c|c|c|c|c|c|c|c|c|c|c|}
\hline \multirow[t]{2}{*}{ Source } & \multirow{2}{*}{ Variations } & \multicolumn{4}{|c|}{$\begin{array}{c}\text { Total Phenolic Content } \\
(\mathrm{mg} / \mathrm{g})\end{array}$} & \multicolumn{4}{|c|}{$\begin{array}{c}\text { Total Flavonoid Content } \\
(\mathrm{mg} / \mathrm{g})\end{array}$} & \multicolumn{4}{|c|}{$\begin{array}{c}\text { DPPH } \\
(\%)\end{array}$} \\
\hline & & Water & Acetone & Ethanol & Methanol & Water & Acetone & Ethanol & Methanol & Water & Acetone & Ethanol & Methanol \\
\hline \multirow{2}{*}{ Slopes } & North & $12.00^{\mathrm{b}}$ & $30.29^{b}$ & $21.00^{\mathrm{b}}$ & $29.00^{\mathrm{a}}$ & $10.74^{\mathrm{a}}$ & $20.33^{b}$ & $18.89^{\mathrm{a}}$ & $20.67^{a}$ & $11.11^{\mathrm{a}}$ & $50.89^{b}$ & $43.00^{\mathrm{b}}$ & $54.37^{\mathrm{a}}$ \\
\hline & South & $14.22^{\mathrm{a}}$ & $33.25^{\mathrm{a}}$ & $27.11^{\mathrm{a}}$ & $21.56^{\mathrm{b}}$ & $9.741^{\mathrm{b}}$ & $28.33^{\mathrm{a}}$ & $14.89^{\mathrm{b}}$ & $19.78^{b}$ & $9.77^{\mathrm{b}}$ & $55.22^{\mathrm{a}}$ & $44.55^{\mathrm{a}}$ & $42.44^{b}$ \\
\hline \multirow{3}{*}{ Altitude } & Top & $13.67^{b}$ & $35.05^{b}$ & $26.16^{\mathrm{b}}$ & $27.33^{b}$ & $10.61^{b}$ & $26.67^{b}$ & $17.00^{\mathrm{b}}$ & $22.50^{\mathrm{a}}$ & $10.67^{b}$ & $56.33^{\mathrm{a}}$ & $45.33^{b}$ & $42.55^{\mathrm{c}}$ \\
\hline & Mid & $10.83^{\mathrm{c}}$ & $23.83^{c}$ & $17.33^{\mathrm{c}}$ & $17.94^{\mathrm{c}}$ & $6.94^{c}$ & $17.16^{\mathrm{c}}$ & $14.00^{c}$ & $17.67^{c}$ & $7.50^{c}$ & $51.00^{\mathrm{b}}$ & $36.33^{c}$ & $47.67^{\mathrm{b}}$ \\
\hline & Bottom & $14.83^{\mathrm{a}}$ & $36.44^{\mathrm{a}}$ & $28.67^{\mathrm{a}}$ & $30.56^{\mathrm{a}}$ & $13.16^{\mathrm{a}}$ & $29.16^{\mathrm{a}}$ & $19.67^{\mathrm{a}}$ & $20.50^{\mathrm{b}}$ & $13.16^{\mathrm{a}}$ & $51.83^{b}$ & $49.67^{a}$ & $55.00^{\mathrm{a}}$ \\
\hline \multirow{3}{*}{$\begin{array}{c}\text { Growth } \\
\text { stages }\end{array}$} & Green & $15.50^{\mathrm{a}}$ & $29.33^{c}$ & $23.33^{b}$ & $24.33^{\mathrm{b}}$ & $10.00^{\mathrm{b}}$ & $21.67^{b}$ & $13.83^{c}$ & $20.33^{b}$ & $10.00^{\mathrm{b}}$ & $53.67^{a}$ & $44.67^{\mathrm{a}}$ & $42.83^{c}$ \\
\hline & Purple & $12.50^{\mathrm{b}}$ & $30.22^{\mathrm{b}}$ & $23.00^{\mathrm{b}}$ & $25.22^{\mathrm{b}}$ & $8.44^{c}$ & $21.16^{\mathrm{b}}$ & $17.67^{\mathrm{b}}$ & $19.00^{\mathrm{c}}$ & $8.50^{\mathrm{c}}$ & $52.33^{\mathrm{b}}$ & $43.67^{\mathrm{b}}$ & $48.72^{\mathrm{b}}$ \\
\hline & Black & $11.33^{\mathrm{c}}$ & $35.77^{\mathrm{a}}$ & $25.83^{\mathrm{a}}$ & $26.27^{\mathrm{a}}$ & $12.27^{\mathrm{a}}$ & $30.16^{\mathrm{a}}$ & $19.16^{\mathrm{a}}$ & $21.33^{\mathrm{a}}$ & $12.83^{\mathrm{a}}$ & $53.16^{\mathrm{ab}}$ & $43.00^{\mathrm{b}}$ & $53.67^{\mathrm{a}}$ \\
\hline
\end{tabular}

Different letters show significant difference between the groups $(\mathrm{P}<0.05)$

Analysis of variance study clearly shows significant differences between results of TPC, TFC and AA in response to different slope directions, altitudes and growth stages (Tables 3,4,5). 


$$
-21 \text { - }
$$

Table 3. Factorial analysis of variance for total Phenolic content on the basis of different slopes, altitudes, growth stages and extraction in different solvents

\begin{tabular}{c|c|cc|cc|cc|cc}
\hline \multirow{2}{*}{ Sources } & \multirow{2}{*}{ DF } & \multicolumn{2}{|c|}{ Water } & \multicolumn{2}{|c|}{ Acetone } & \multicolumn{2}{c|}{$\mathbf{8 0 \%}$ Ethanol } & \multicolumn{2}{c}{$\mathbf{8 0 \% \text { Methanol }}$} \\
\cline { 3 - 9 } & & $\mathbf{F}$ & $\mathbf{P}$ & $\mathbf{F}$ & $\mathbf{P}$ & $\mathbf{F}$ & $\mathbf{P}$ & $\mathbf{F}$ & $\mathbf{P}$ \\
\hline Replicate & 2 & & & & & & & & \\
Slopes & 1 & 37.99 & 0.00 & 79.71 & 0.00 & 519.44 & 0.00 & 360.53 & 0.00 \\
Altitude & 2 & 43.4 & 0.00 & 578.86 & 0.00 & 657.51 & 0.00 & 372.37 & 0.00 \\
Growth & 2 & 47.39 & 0.00 & 147.66 & 0.00 & 44.47 & 0.00 & 8.22 & 0.00 \\
Slopes*Altitude & 2 & 14.34 & 0.00 & 7.71 & 0.00 & 39.32 & 0.00 & 37.45 & 0.00 \\
Slopes*Growth & 2 & 0.66 & 0.52 & 196.13 & 0.00 & 58.90 & 0.00 & 107.01 & 0.00 \\
Altitude*Growth & 4 & 2.37 & 0.07 & 12.80 & 0.00 & 1.72 & 0.17 & 3.27 & 0.02 \\
Slopes*Altitude*Growth & 4 & 3.51 & 0.02 & 83.84 & 0.00 & 2.23 & 0.09 & 14.35 & 0.00 \\
\hline
\end{tabular}

Significant at $\mathrm{p}<0.05$

Table 4. Factorial analysis of variance for total Flavonoid content on the basis of different slopes, altitudes, growth stages and extraction in different solvents

\begin{tabular}{c|c|cc|cc|cc|cc}
\hline \multirow{2}{*}{ Sources } & \multirow{2}{*}{ DF } & \multicolumn{2}{|c|}{ Water } & \multicolumn{2}{c|}{ Acetone } & \multicolumn{2}{c|}{ Ethanol } & \multicolumn{2}{c}{ Methanol } \\
\cline { 3 - 9 } & & F & $\mathbf{P}$ & $\mathbf{F}$ & $\mathbf{P}$ & $\mathbf{F}$ & $\mathbf{P}$ & $\mathbf{F}$ & $\mathbf{P}$ \\
\hline Replicate & 2 & & & & & & & & \\
Slopes & 1 & 5.70 & 0.02 & 366.18 & 0.00 & 269.78 & 0.00 & 32.97 & 0.00 \\
Altitude & 2 & 74.35 & 0.00 & 305.79 & 0.00 & 180.69 & 0.00 & 328.15 & 0.00 \\
Growth & 2 & 28.25 & 0.00 & 195.17 & 0.00 & 170.07 & 0.00 & 76.24 & 0.00 \\
Slopes*Altitude & 2 & 8.54 & 0.00 & 6.57 & 0.00 & 52.46 & 0.00 & 219.97 & 0.00 \\
Slopes*Growth & 2 & 40.84 & 0.00 & 51.07 & 0.00 & 247.92 & 0.00 & 496.61 & 0.00 \\
Altitude*Growth & 4 & 6.62 & 0.00 & 13.99 & 0.00 & 14.57 & 0.00 & 113.33 & 0.00 \\
Slopes*Altitude*Growth & 4 & 9.13 & 0.00 & 16.95 & 0.00 & 47.46 & 0.00 & 122.61 & 0.00 \\
\hline
\end{tabular}

Significant at $\mathrm{p}<0.05$

Table 5. Factorial analysis of variance for total DPPH radical scavenging activity on the basis of different slopes, altitudes, growth stages and extraction in different solvents

\begin{tabular}{c|c|cc|cc|cc|cc}
\hline Source & \multirow{2}{*}{ DF } & \multicolumn{2}{|c|}{ Water } & \multicolumn{2}{c|}{ Acetone } & \multicolumn{2}{c|}{ Ethanol } & \multicolumn{2}{c}{ Methanol } \\
& & F & P & F & P & F & P & F & P \\
\hline Replicate & 2 & & & & & & & & \\
Slopes & 1 & 48.32 & 0.00 & 164.00 & 0.00 & 31.14 & 0.00 & 4033.47 & 0.00 \\
Altitude & 2 & 292.24 & 0.00 & 95.85 & 0.00 & 793.76 & 0.00 & 1479.51 & 0.00 \\
Growth & 2 & 175.48 & 0.00 & 5.28 & 0.01 & 12.07 & 0.00 & 1112.24 & 0.00 \\
Slopes*Altitude & 2 & 19.13 & 0.00 & 18.44 & 0.00 & 31.14 & 0.00 & 406.29 & 0.00 \\
Slopes*Growth & 2 & 248.62 & 0.00 & 347.73 & 0.00 & 27.33 & 0.00 & 44.62 & 0.00 \\
Altitude*Growth & 4 & 25.00 & 0.00 & 110.25 & 0.00 & 3.26 & 0.02 & 143.99 & 0.00 \\
Slopes*Altitude*Growth & 4 & 27.68 & 0.00 & 17.31 & 0.00 & 18.03 & 0.00 & 65.80 & 0.00 \\
\hline
\end{tabular}

Significant at $\mathrm{p}<0.05$

Results of the present study showed that TPC of olive fruits showed the highest ranges $(21-51 \mathrm{mg} / \mathrm{g})$ when extracted in acetone i.e., in opposition with the study of Kamran (2016) who stated that organic solvents are not applicable for the extraction of phenolic acids. These compounds are mainly bound by ester or glycosidic links to the cell wall (Ignat et al., 2011). Therefore, release of these compounds requires acid or base hydrolysis (Kamran, 2016). 
After acetone, $80 \%$ methanol, $80 \%$ ethanol and water stood second, third and fourth for better recovery of TPC, TFC and AA as DPPH radical scavenging activity of olive fruit extracts (Fig. 6).

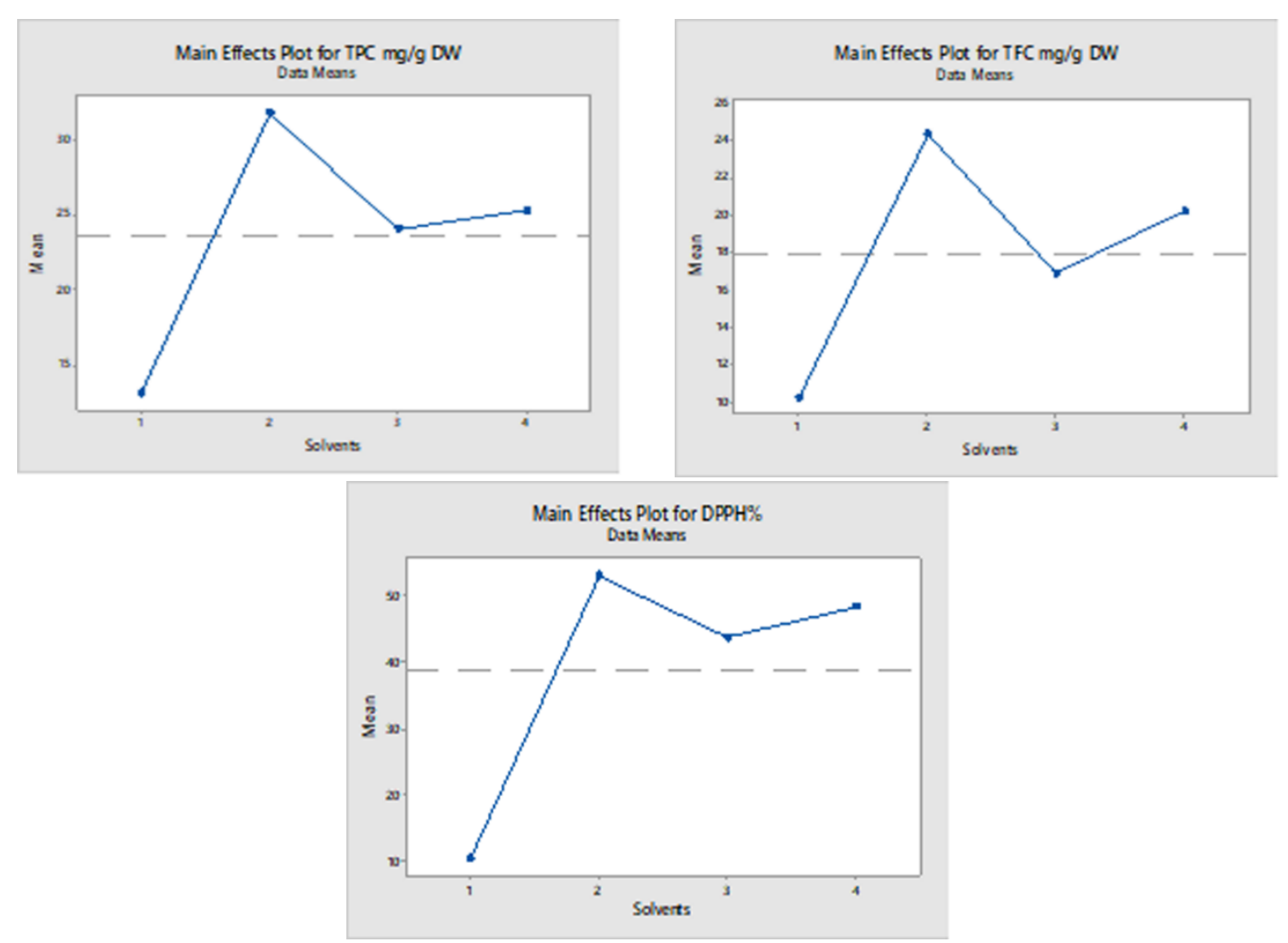

Figure 6. Main effect plot for total phenolic content, total flavonoid contents, and antioxidant activity of Olea ferruginea Royle fruits with respect to four extraction solvents. Solvents: $1=$ water, $2=$ acetone, $3=80 \%$ ethanol, $4=80 \%$ methanol

\section{Conclusion}

Olea ferruginea Royale is a commercially underutilized species of naturally occurring olives of Zhob. As this species of olive has small sized fruit and recently oil is main demand from the Olea sp. commercially it is underutilized and a way it is a neglected species of olive. But this study revealed the importance of fruit extract to be used in pharmaceutical industry as the fruit is locally used in various ailments. Present work may contribute to finding of the best harvesting time, elevation and slope direction that can help to avail maximum TPC, TFC and AA in olive fruits. It can be concluded that all three studied factors have a strong impact on the quantity of secondary metabolites and radical scavenging capacity. Safely it can be stated according to recent findings that for maximum recovery of polyphenols and a good antioxidant activity, olives can be picked when fully matured. Considering altitudinal impact, it was found that good amount of phenolics can be extracted from olives collected from both extremes i.e., the highest and the lowest altitudes among sampling sites according to the present study. The study also aimed to check the potency of profitable exploitation of olives coming from an underutilized widely distributed species of District Zhob that is non-commercial right now. This can help to boost local income and benefit consumers, industries, markets, and society. 
Acknowledgements. Authors are very thankful to Professor Emeritus Dr. Akhtar Muhammad Kasi, Department of Geology, University of Balochistan Quettta and Professor Dr. Aimal Kasi, Centre of Excellence in Mineralogy, University of Balocistan Quetta for their technical support during field work and for providing scientific gadgets and maps. Authors are thankful to Nisar Ahmed, Assistant Director at Geological Survey of Pakistan Quetta for his help in preparing area map.

\section{REFERENCES}

[1] Ahmad, S. S. (2007): Medicinal wild plants from Lahore-Islamabad motorway (M-2). Pakistan Journal of Botany 39: 355.

[2] Ahmad, M., Qureshi, R., Arshad, M., Khan, M. A., Zafar, M. (2009): Traditional herbal remedies used for the treatment of diabetes from district Attock (Pakistan). - Pak J Bot 41: 2777-82.

[3] Ahmad-Qasem, M. H., Barrajón-Catalán, E., Micol, V., Mulet, A., García-Pérez, J. V. (2013): Influence of freezing and dehydration of olive leaves (var. Serrana) on extract composition and antioxidant potential. - Food Research International 50(1): 189-196.

[4] Amiot, M. J., Fleuriet, A., Macheix, J. J. (1986): Importance and evolution of phenolic compounds in olive during growth and maturation. - Journal of Agricultural and Food Chemistry 34: 823-826.

[5] Bouaziz, M., Chamkha, M., Sayadi, S. (2004): Comparative study on phenolic content and antioxidant activity during maturation of the olive cultivar Chemlali from Tunisia. Journal of Agricultural and Food Chemistry 52: 5476-5481.

[6] Dewanto, V., Wu, X., Adom, K. K., Liu, R. H. (2002): Thermal processing enhances the nutritional value of tomatoes by increasing total antioxidant activity. - Journal of Agricultural and Food Chemistry 50: 3010-3014.

[7] Folin, O., Denis, W. (1912): On phosphotungstic-phosphomolybdic compounds as color reagents. - Journal of Biological Chemistry 12: 239-243.

[8] Ghanbari, R., Anwar, F., Alkharfy, K. M., Gilani, A.-H., Saari, N. (2012): Valuable nutrients and functional bioactives in different parts of olive (Olea europaea L.) - a review. - International Journal of Molecular Sciences 13: 3291-3340.

[9] Grohmann, F. (1974): Flora of West Pakistan: Oleaceae. - University of Karachi.

[10] Hung, P., Duy, T. (2012): Effects of drying methods on bioactive compounds of vegetables and correlation between bioactive compounds and their antioxidants. International Food Research Journal 19: 327.

[11] Ignat, I., Volf, I., Popa, V. I. (2011): A critical review of methods for characterisation of polyphenolic compounds in fruits and vegetables. - Food chemistry 126: 1821-1835.

[12] Imaga, N. A., Gbenle, G. O., Okochi, V. I., Adenekan, S., Duro-Emmanuel, T., Oyeniyi, B., Dokai, P. N., Oyenuga, M., Otumara, A., Ekeh, F. C. (2010): Phytochemical and antioxidant nutrient constituents of Carica papaya and Parquetina nigrescens extracts. Scientific Research and Essays 5(16): 2201-2205.

[13] Kamran, M. (2016): Olive (Olea europaea L.) leaf biophenols as nutraceuticals. Master's Thesis, Charles Sturt University.

[14] Malik, N. S., Bradford, J. M. (2008): Recovery and stability of oleuropein and other phenolic compounds during extraction and processing of olive (Olea europaea L.) leaves. - Journal of Food Agriculture and Environment 6: 8.

[15] Måren, I. E., Karki, S., Prajapati, C., Yadav, R. K., Shrestha, B. B. (2015): Facing north or south: Does slope aspect impact forest stand characteristics and soil properties in a semiarid trans-Himalayan valley? - Journal of Arid Environments 121: 112-123.

[16] Pereira, A., Ferreira, I., Marcelino, F., Valentão, P., Andrade, P., Seabra, R., Estevinho, L., Bento, A., Pereira, J. (2007): Phenolic compounds and antimicrobial activity of olive (Olea europaea L. Cv. Cobrançosa) leaves. - Molecules 12: 1153-1162. 
[17] Poudyal, H., Campbell, F., Brown, L. (2010): Olive leaf extract attenuates cardiac, hepatic, and metabolic changes in high carbohydrate-, high fat-fed rats. - The Journal of Nutrition 140: 946-953.

[18] Queiroz, L. P. D. (2009): Leguminosas da caatinga. - Universidad Estadual de Feira de Santana.

[19] Sariyildiz, T., Anderson, J., Kucuk, M. (2005): Effects of tree species and topography on soil chemistry, litter quality, and decomposition in Northeast Turkey. - Soil Biology and Biochemistry 37: 1695-1706.

[20] Sharma, R., Kundra, R., Samant, S., Nandi, S. (2017): Antioxidant Properties of Methanol Extracts from Olea ferruginea Royle Seeds. - National Academy science letters 40: 379-382.

[21] Zabihullah, Q., Rashid, A., Akhtar, N. (2006): Ethnobotanical survey in kot Manzaray Baba valley Malakand agency, Pakistan. - Pak J Plant Sci 12: 115-121.

\section{APPENDIX}

Table A1. Total Phenolic Content $(\mathrm{mg} / \mathrm{g})$ in fruits of Olea ferruginea at different altitudes, slopes, growth stages and extracted in four solvents

\begin{tabular}{|c|c|c|c|c|c|c|c|c|c|}
\hline \multirow[b]{2}{*}{ Altitude } & \multirow{2}{*}{$\begin{array}{c}\text { Growth } \\
\text { stages }\end{array}$} & \multicolumn{4}{|c|}{ Northern slopes } & \multicolumn{4}{|c|}{ Southern slopes } \\
\hline & & Acetone & Water & $\begin{array}{c}\mathbf{8 0 \%} \\
\text { Ethanol } \\
\end{array}$ & $\begin{array}{c}\mathbf{8 0 \%} \\
\text { Methanol } \\
\end{array}$ & Acetone & Water & $\begin{array}{c}\mathbf{8 0 \%} \\
\text { Ethanol } \\
\end{array}$ & $\begin{array}{c}\mathbf{8 0 \%} \\
\text { Methanol } \\
\end{array}$ \\
\hline \multirow{3}{*}{ Top } & Green fruit & $32 \pm 1$ & $15 \pm 3$ & $22 \pm 3$ & $25 \pm 1.7$ & $37 \pm 1$ & $17 \pm 2$ & $28 \pm 1$ & $28 \pm 1$ \\
\hline & Purple fruit & $21 \pm 1$ & $11 \pm 2$ & $12 \pm 2$ & $19 \pm 1$ & $21 \pm 1$ & $15 \pm 0$ & $22 \pm 1$ & $17 \pm 1$ \\
\hline & Black fruit & $41 \pm 4$ & $18 \pm 2$ & $24 \pm 2$ & $28 \pm 1.7$ & $24 \pm 2.5$ & $17 \pm 0$ & $32 \pm 1$ & $29 \pm 1$ \\
\hline \multirow{3}{*}{ Mid } & Green fruit & $34 \pm 1$ & $10 \pm 1.7$ & $25 \pm 1.7$ & $32 \pm 1$ & $34 \pm 2.6$ & $15 \pm 1$ & $25 \pm 1$ & $22 \pm 1$ \\
\hline & Purple fruit & $22 \pm 2.6$ & $8 \pm 1$ & $14 \pm 1.7$ & $21 \pm 1.7$ & $22 \pm 1$ & $12 \pm 1$ & $19 \pm 1$ & $15 \pm 0$ \\
\hline & Black fruit & $43 \pm 3$ & $16 \pm 1$ & $27 \pm 1$ & $40 \pm 1$ & $37 \pm 1$ & $14 \pm 0$ & $28 \pm 1$ & $21 \pm 1.5$ \\
\hline \multirow{3}{*}{ Bottom } & Green fruit & $32 \pm 2.6$ & $12 \pm 1$ & $26 \pm 1$ & $32 \pm 1$ & $42 \pm 1$ & $13 \pm 1$ & $31 \pm 2$ & $25 \pm 1$ \\
\hline & Purple fruit & $25 \pm 3$ & $7 \pm 1$ & $12 \pm 2$ & $22 \pm 1$ & $32 \pm 1$ & $12 \pm 1$ & $25 \pm 1$ & $17 \pm 1$ \\
\hline & Black fruit & $33 \pm 1.5$ & $11 \pm 1$ & $27 \pm 1$ & $42 \pm 1$ & $51 \pm 1$ & $13 \pm 1$ & $34 \pm 2$ & $23 \pm 1.7$ \\
\hline
\end{tabular}

Values presented as mean and \pm Standard deviation

Table A2. Total Flavonoid Content $(\mathrm{mg} / \mathrm{g}$ ) in fruits of Olea ferruginea at different altitudes, slopes, growth stages and extracted in four solvents

\begin{tabular}{|c|c|c|c|c|c|c|c|c|c|}
\hline \multirow[b]{2}{*}{ Altitude } & \multirow{2}{*}{$\begin{array}{c}\text { Growth } \\
\text { stages }\end{array}$} & \multicolumn{4}{|c|}{ Northern slopes } & \multicolumn{4}{|c|}{ Southern slopes } \\
\hline & & Acetone & Water & $\begin{array}{c}\mathbf{8 0 \%} \\
\text { Ethanol }\end{array}$ & $\begin{array}{c}80 \% \\
\text { Methanol } \\
\end{array}$ & Acetone & Water & $\begin{array}{c}\mathbf{8 0 \%} \\
\text { Ethanol }\end{array}$ & $\begin{array}{c}\mathbf{8 0 \%} \\
\text { Methanol } \\
\end{array}$ \\
\hline \multirow{3}{*}{ Top } & Green fruit & $22 \pm 2.6$ & $9 \pm 1$ & $15 \pm 1$ & $19 \pm 1$ & $22 \pm 1$ & $11 \pm 1$ & $15 \pm 1$ & $22 \pm 1.0$ \\
\hline & Purple fruit & $12 \pm 1$ & $5 \pm 0$ & $9 \pm 1$ & $23 \pm 1$ & $19 \pm 1$ & $9 \pm 1$ & $11 \pm 1$ & $13 \pm 0$ \\
\hline & Black fruit & $27 \pm 2.6$ & $11 \pm 1$ & $12 \pm 1$ & $25 \pm 0$ & $28 \pm 7$ & $15 \pm 0$ & $21 \pm 1$ & $20 \pm 1.0$ \\
\hline \multirow{3}{*}{ Mid } & Green fruit & $18 \pm 2$ & $11 \pm 0$ & $19 \pm 1$ & $27 \pm 1$ & $32 \pm 1$ & $9 \pm 1.1$ & $18 \pm 2.6$ & $21 \pm 1.7$ \\
\hline & Purple fruit & $11 \pm 1$ & $6 \pm 1$ & $21 \pm 1$ & $22 \pm 1$ & $19 \pm 1$ & $6 \pm 1$ & $8 \pm 0$ & $11 \pm 1.0$ \\
\hline & Black fruit & $22 \pm 3$ & $9 \pm 1$ & $25 \pm 0$ & $15 \pm 1$ & $25 \pm 2$ & $10 \pm 1$ & $15 \pm 1$ & $18 \pm 1.7$ \\
\hline \multirow{3}{*}{ Bottom } & Green fruit & $25 \pm 2.6$ & $15 \pm 1$ & $19 \pm 1$ & $21 \pm 0$ & $41 \pm 2.6$ & $9 \pm 1$ & $16 \pm 1$ & $25 \pm 1.7$ \\
\hline & Purple fruit & $17 \pm 1$ & $11 \pm 0$ & $23 \pm 2$ & $16 \pm 1$ & $25 \pm 1$ & $8 \pm 0$ & $12 \pm 1$ & $21 \pm 1.0$ \\
\hline & Black fruit & $29 \pm 1$ & $23 \pm 1$ & $27 \pm 1$ & $18 \pm 1$ & $44 \pm 2$ & $11 \pm 2$ & $18 \pm 1.7$ & $27 \pm 1.0$ \\
\hline
\end{tabular}

Values presented as mean and \pm Standard deviation 


$$
-25-
$$

Table A3. Antioxidant activity as DPPH radical scavenging activity (\%) in fruits of Olea ferruginea at different altitudes, slopes, growth stages and extracted in four solvents

\begin{tabular}{c|c|cccc|cccc}
\hline \multirow{3}{*}{ Altitudes } & Growth & \multicolumn{4}{|c|}{ Northern slopes } & \multicolumn{4}{c}{ Southern slopes } \\
\cline { 3 - 9 } & stages & Acetone & Water & $\begin{array}{c}80 \% \\
\text { Ethanol }\end{array}$ & $\begin{array}{c}80 \% \\
\text { Methanol }\end{array}$ & Acetone & Water & $\begin{array}{c}80 \% \\
\text { Ethanol }\end{array}$ & $\begin{array}{c}80 \% \\
\text { Methanol }\end{array}$ \\
\hline \multirow{3}{*}{ Top } & Green fruit & $58 \pm 2.6$ & $35 \pm 0$ & $44 \pm 1$ & $26 \pm 2.6$ & $66 \pm 2$ & $42 \pm 1$ & $47 \pm 1$ & $36 \pm 1.0$ \\
& Purple fruit & $40 \pm 1$ & $48 \pm 1$ & $35 \pm 2$ & $45 \pm 1$ & $43 \pm 2$ & $32 \pm 1$ & $40 \pm 1$ & $23 \pm 0$ \\
& Black fruit & $52 \pm 1$ & $62 \pm 1$ & $50 \pm 1$ & $60 \pm 1$ & $53 \pm 2.6$ & $48 \pm 1$ & $52 \pm 2$ & $42 \pm 1.0$ \\
\hline \multirow{5}{*}{ Mid } & Green fruit & $60 \pm 1$ & $35 \pm 0$ & $42 \pm 2$ & $40 \pm 2$ & $52 \pm 2$ & $30 \pm 0$ & $48 \pm 1$ & $39 \pm 1.0$ \\
& Purple fruit & $54 \pm 2.6$ & $50 \pm 1$ & $38 \pm 2$ & $59 \pm 2$ & $32 \pm 1$ & $42 \pm 0$ & $35 \pm 0$ & $22 \pm 1.0$ \\
& Black fruit & $52 \pm 3.6$ & $64 \pm 0$ & $47 \pm 1$ & $65 \pm 1$ & $44 \pm 0$ & $58 \pm 1$ & $52 \pm 1$ & $50 \pm 0$ \\
\hline \multirow{5}{*}{ Bottom } & Green fruit & $57 \pm 2.6$ & $33 \pm 2$ & $44 \pm 1.7$ & $56 \pm 2$ & $45 \pm 1$ & $21 \pm 1$ & $47 \pm 1$ & $46 \pm 1.7$ \\
& Purple fruit & $51 \pm 2$ & $52 \pm 0$ & $38 \pm 1$ & $61 \pm 1$ & $32 \pm 0$ & $19 \pm 1$ & $32 \pm 1$ & $23 \pm 1.0$ \\
& Black fruit & $62 \pm 2$ & $63 \pm 1$ & $49 \pm 1$ & $65 \pm 1$ & $48 \pm 1$ & $25 \pm 0$ & $48 \pm 1$ & $48 \pm 1.0$ \\
\hline
\end{tabular}

Values presented as mean and \pm Standard deviation 